\title{
World-Wide Character of the Progressive Change in the Disturbance Forces of Geomagnetic Bays*
}

\author{
By Naoshi FUKUSHIMA and Hironori ŌNO \\ (Geophysical Institute, Tokyo University)
}

\begin{abstract}
The vector-diagrams illustrating the change in the disturbance forces during the whole course of geomagnetic bays, show the same characteristics everywhere in the middle latitude regions; namely the disturbance force vector rotates clockwise with time in the forenoon and counter-clockwise in the afternoon, and the above characteristic corresponds to broadening of the positive bay area over the earth's surface during the course of bay. It is also noticed that the average current system of bay disturbance tends to shift eastward on the whole during its development and decay processes.

In the disturbance force of bays observed at Sitka, the influence of the auroral zone current is clearly seen. On the other hand, the disturbance force at Honolulu is so small in its magnitude that the bays' character is less systematic there compared with those in the middle latitude regions.
\end{abstract}

\section{§ 1. Introduction}

Vector-diagrams of the horizontal disturbing forces during the course of bay disturbances have been examined by L. Steiner [1], H. Hatakeyama [2] and J.Ma Príncep Curto [3] with the aid of a number of data at $\mathrm{O}^{\prime}$ Gyalla $\left(47^{\circ} 52^{\prime} \mathrm{N}, 18^{\circ} 11^{\prime} \mathrm{E}\right)$, Toyohara $\left(46^{\circ} 58^{\prime} \mathrm{N}, 142^{\circ} 45^{\prime} \mathrm{E}\right)$ and Ebro $\left(40^{\circ} 49^{\prime} \mathrm{N}, 0^{\circ} 31^{\prime} \mathrm{E}\right)$ respectively. A well-known character of the mean vector-diagram, which is common for the above three stations in the middle latitude regions, is to form a loop during the course of the bay disturbance, and the sense of its rotation depends upon the local time, namely clockwise in the forenoon and counterclockwise in the afternoon.

It will be examined in this paper that whether the above-mentioned characteristic of the looping phenomenon of the bay disturbance can be also seen in the records of American middle latitude stations, Cheltenham $\left(38^{\circ} 44^{\prime} \mathrm{N}, 76^{\circ} 50^{\prime} \mathrm{W}\right)$ and Tucson $\left(32^{\circ} 15^{\prime} \mathrm{N}, 110^{\circ} 50^{\prime} \mathrm{W}\right)$. The observational results at Sitka $\left(57^{\circ} 04^{\prime} \mathrm{N}, 135^{\circ} 20^{\prime} \mathrm{W}\right)$ and Honolulu $\left(21^{\circ} 19^{\prime} \mathrm{N}, 158^{\circ} 04^{\prime} \mathrm{W}\right)$ were also examined in order to study the characteristics of the bay disturbance at the higher and lower latitude stations.

* Contribution from Division of Geomagnetism and Geoelectricity, Geophysical Institute, Tokyo University. Series II, No. 34. 


\section{§ 2. Data and method of analysis}

“Magnetograms" published by U.S. Coast and Geodetic Survey were available in this study. The data during 1947 and 1948 were used for Cheltenham and Tucson, while for Sitka, the records during three years, 1946-1948, and for Honolulu, Jan. 1946 through June 1949, were analysed.

The whole duration of a bay disturbance was divided into six parts; the time of its beginning is denoted by $t_{0}$ and that of its end by $t_{6}$, while $t_{3}$ means the middle of the whole duration. The disturbance force of bays was defined approximately to be the deviation from the straight line connecting the values at $t_{0}$ and $t_{6}$ on magnetograms. Whole selected bay disturbances were divided into eight groups according as $t_{3}$ s belong to $0-3 \mathrm{~h}, 3-6 \mathrm{~h},---, 21-24 \mathrm{~h}$ in local time. Numbers of selected bays are tabulated below.

Number of bays during respective intervals of local time

$\begin{array}{lccrcccccc}\text { Observation } & 0-3^{\mathbf{h}} & 3-6^{\mathbf{h}} & 6-9^{\mathbf{h}} & 9-12^{\mathbf{h}} & 12-15^{\mathbf{h}} & 15-18^{\mathbf{h}} & 18-21^{\mathbf{h}} & 21-24^{\mathbf{h}} & \text { Total } \\ \text { Cheltenham } & 41 & 42 & 18 & 12 & 15 & 26 & 29 & 49 & 232 \\ \text { Tucson } & 45 & 27 & 5 & 11 & 22 & 31 & 39 & 48 & 228 \\ \text { Sitka } & 56 & 50 & 18 & 12 & 8 & 10 & 39 & 80 & 273 \\ \text { Honolulu } & 53 & 20 & 5 & 38 & 20 & 40 & 33 & 69 & 279\end{array}$

\section{§3. Bay disturbances at Cheltenham and Tucson}

The mean vectors of horizontal disturbing forces of bays in each eight time intervals mentioned before for Cheltenham $\left(50.1^{\circ} \mathrm{N}\right.$ in geomagnetic latitude) and Tuscon $\left(40.4^{\circ} \mathrm{N}\right.$ in geomagnetic latitude) are given in Fig. 1 . Diurnal change in the direction

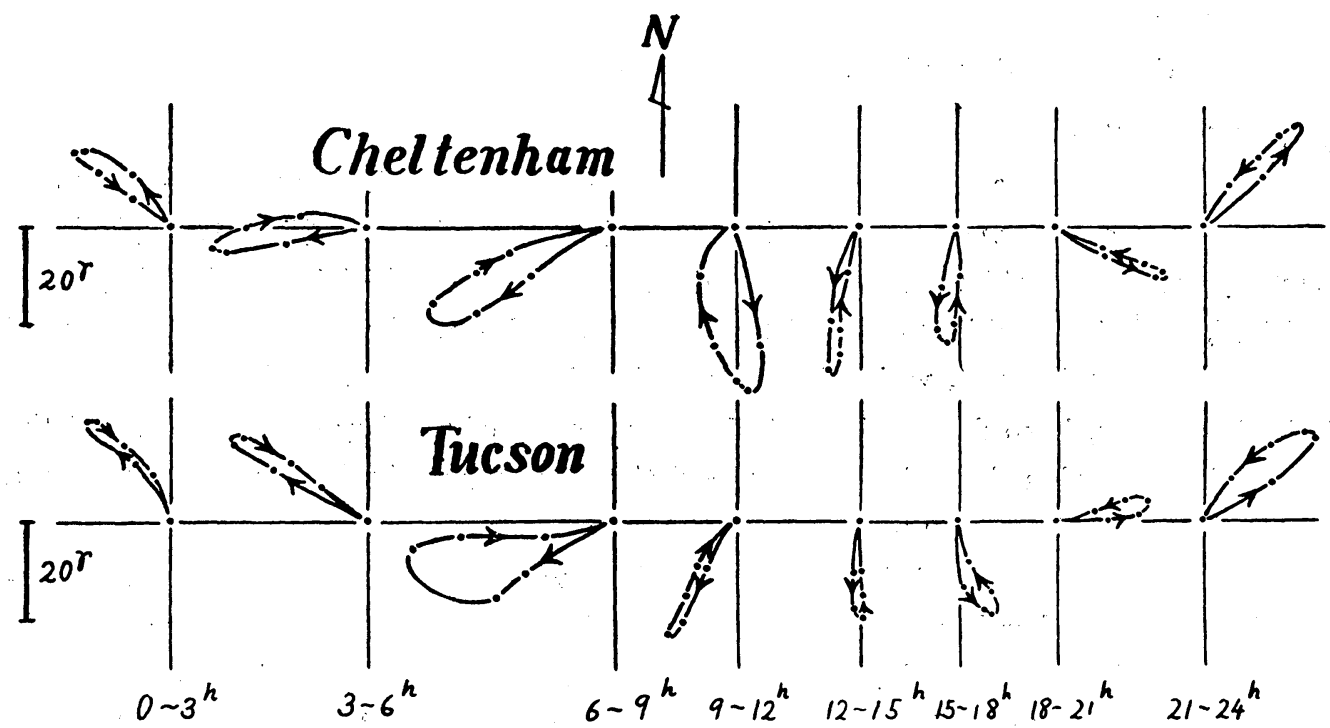

Fig. 1 Vector-diagrams of mean horizontal disturbing forces of geomagnetic bays at Cheltenham and Tucson. (Rectangular axes in the figure are referred to the magnetic north-south and east-west.)

of the disturbing vector has quite the same tendency as those reported hitherto by several investigators; namely, it directs northward at midnight, westward in the 
morning, southward about noon and eastward in the evening, showing counter-clockwise turning in a day. The sense of the rotation of the loops in the vector-diagrams is clockwise in the forenoon and counter-clockwise in the afternoon at both observatories, with only an exceptional one for $0-3 \mathrm{~h}$ at Cheltenham. Therefore, it might be said that the sense of the rotation of the loops just mentioned above will be a general character for every station in the middle latitude regions.

Mean angular velocity of the rotation of horizontal disturbance vectors near the middle of the whole duration of bays, is derived for each loop from the force
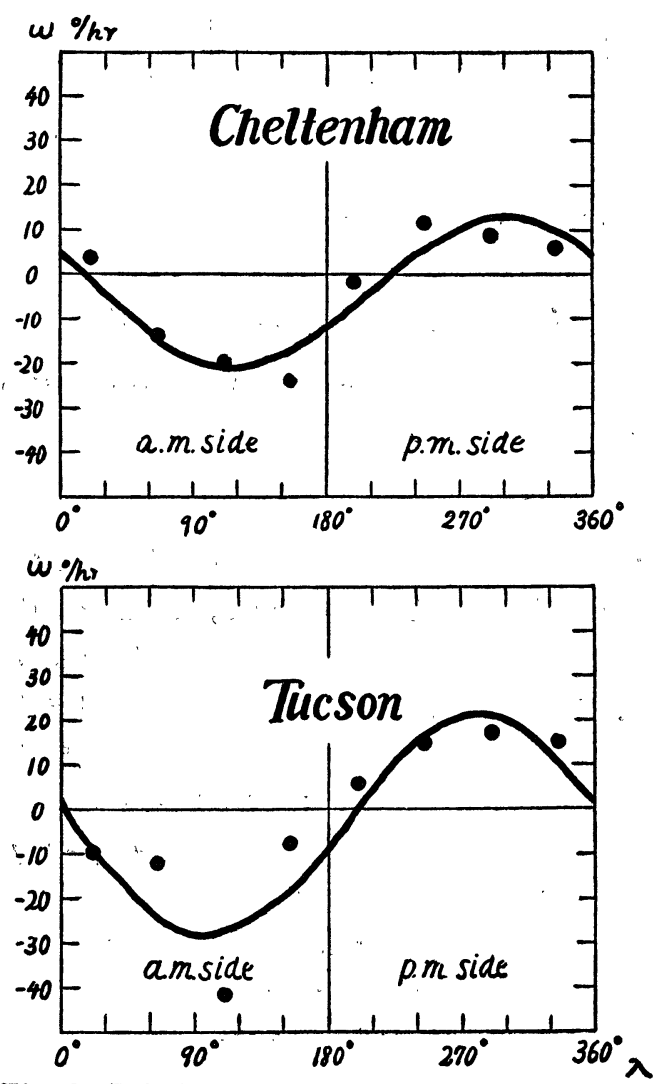

Fig. 2 Relation between $\omega$ and local time $\lambda$. for Cheltenham and Tucson. vectors at $t_{2}$ and $t_{4}$, and denoted by $\omega$. This angular velocity $\omega$ is taken positive or negative according as the rotation of the loop is counter-clockwise or clockwise. The relation between $\omega$ and local time $\lambda$ (replaced by longitude) is shown in Fig. 2. If $\omega$ assumes to be expressed by the form

$$
\omega=a_{0}+c_{1} \sin \left(\lambda+\alpha_{1}\right),
$$

the relations between $\omega$ and $\lambda$ in these two cases are

$$
\begin{array}{cc}
\omega=-3+17 \sin \left(\lambda+150^{\circ}\right) & \circ / \text { hour } \\
& \text { for Cheltenham, } \\
\omega=-3+24 \sin \left(\lambda+169^{\circ}\right) & \begin{array}{c}
\circ \\
\text { hour }
\end{array} \\
\text { for Tucson, }
\end{array}
$$

where the calculations were made under the assumption that the duration of the mean bay disturbance is two hours in every case. On the other hand, the similar expression for the data at Toyohara $\left(36.9^{\circ} \mathrm{N}\right.$ in geomagnetic latitude) during Aub. 1932-Aug. 1935 [2] [4] shows

$$
\omega=-9+46 \sin \left(\lambda+197^{\circ}\right) \quad \% / \text { hour. }
$$

In each cases, the minimum and maximum values of $\omega$ take place in the morning and in the evening respectively. Dynamic behaviour of the current system of bays, which is derived from above-mentioned results, will be discussed in $\S 4$.

\$ 4. The bay disturbance at Sitka, and the current system of the average bay disturbance

The results of similar analysis of the data at Sitka, Alaska, as well as the variation in Z-component are given in Fig. 3. The geomagnetic latitude of the observatory is $60.0^{\circ} \mathrm{N}$. We notice here that the horizontal disturbing vector does not change its direction smoothly counter-clockwise with local time as the cases for Cheltenham and Tucson, but almost southward throughout the forenoon, northward at $12-18 \mathrm{~h}$ and westward at $18-24 \mathrm{~h}$. 

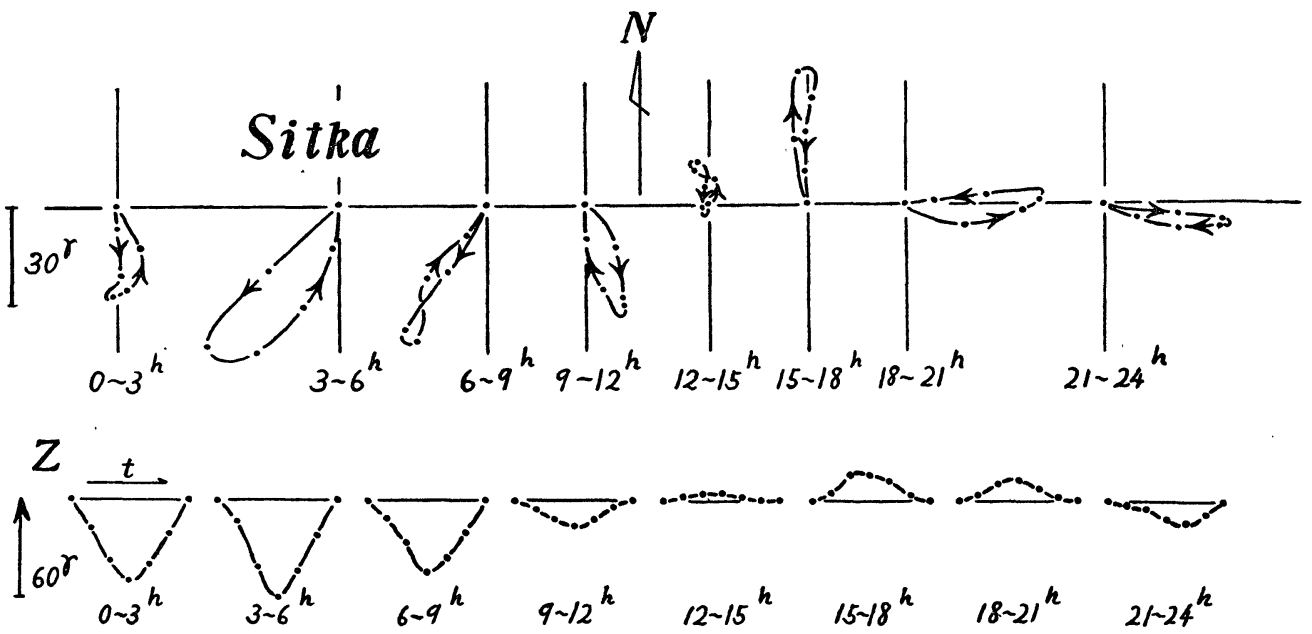

Fig. 3 Vector-diagrams of mean horizontal disturbing forces of bays and simultaneous variation in the vertical intensity observed at Sitka.

Now suppose that the horizontal disturbing force of a bay at a locality on the earth's surface is given by such the vector as given in Figs. 1 and 3, so far as the geomagnetic latitude and local time in these figures are taken as the coordinates of the earth's surface to indicate the locality. We shall call a bay thus defined "the average bay." The equivalent overhead current arrow maps for three stages of the average bay are given in Fig. 4 . The three stages are the developing stage, the maximum stage and the decaying one, represented by the mean state of $t_{1}$ and $t_{2}$, the state at $t_{3}$, and the mean of $t_{4}$ and $t_{5}$, respectively. Stream lines in the maps are so drawn that $2 / 3$ of observed $\mathrm{H}$ - and $\mathrm{D}$-components are taken as external origin parts of respective components, and the simultaneous variation in Z-component is also taken into account. The stream lines, which divide the middle latitude regions into positive and negative bay areas, are drawn with thick lines, where positive or negative bay area means the region in which positive or negative bay is observed respectively. In the middle latitude regions, threre can be seen the tendency that the positive bay area becomes wider and the current system shifts eastward on the whole with the progress of time during the course of the average bay. This characteristic of the current system can be explained by the relation between $\omega$ and $\lambda$ in the preceding paragraph, and a kinematical interpretation was proposed by one of the writers [4].

One can see in Fig. 4 at once that the effect of the auroral zone current is appeared in the disturbance force at Sitka, though the centre of the auroral zone current situates higher than $60^{\circ}$ in geomagnetic latitude. The overhead current system in the polar cap could not be obtained in this study. However, a current system such as given in Fig. 5, which illustrates the average of the current distribution 
World-Wide Character of the Progressive Change in the Disturbance Forces of Geomagnetic Bays 61
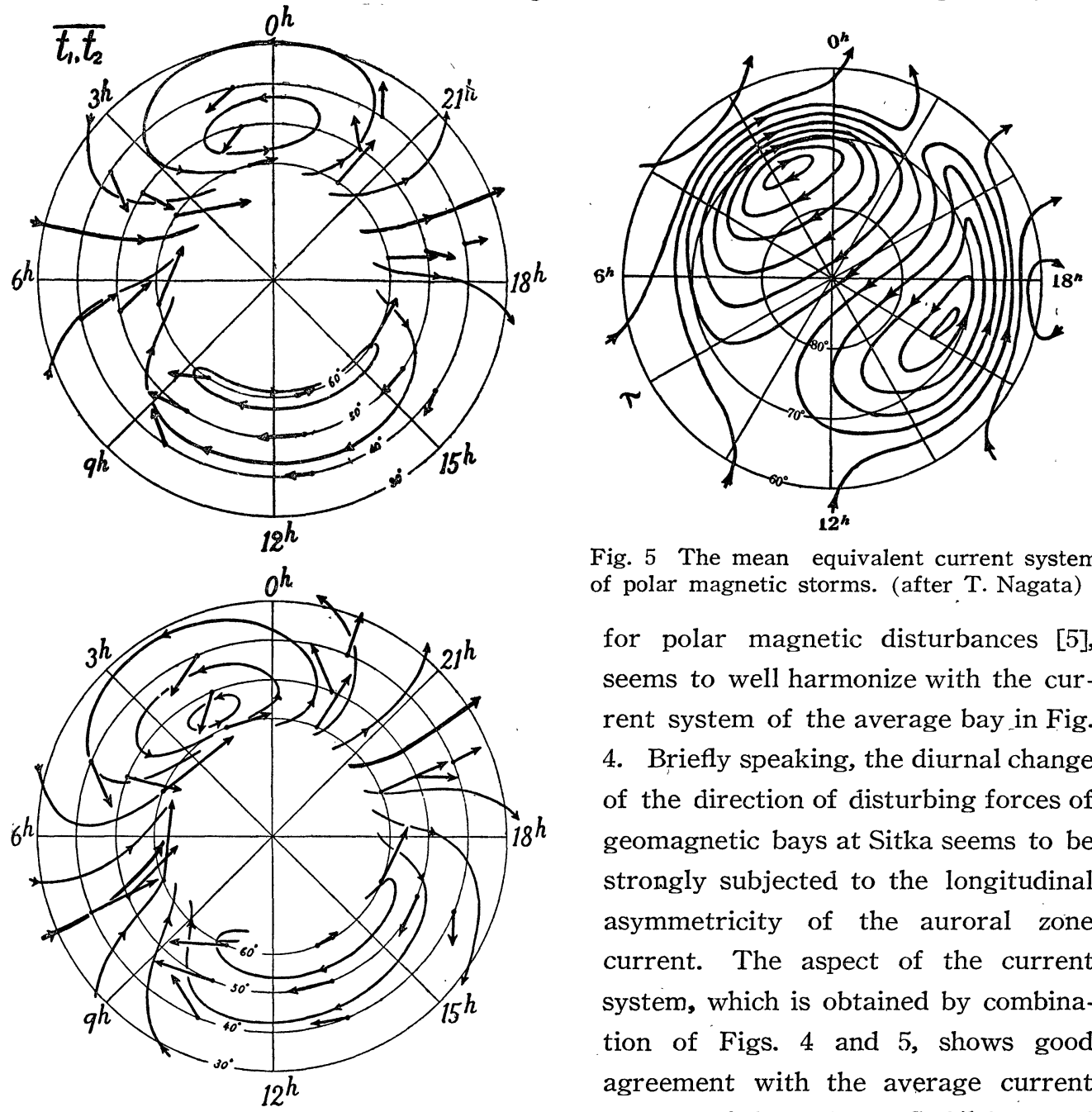

Fig. 5 The mean equivalent current system of polar magnetic storms. (after T. Nagata)

for polar magnetic disturbances [5], seems to well harmonize with the current system of the average bay in Fig. 4. Briefly speaking, the diurnal change of the direction of disturbing forces of geomagnetic bays at Sitka seems to be strongly subjected to the longitudinal asymmetricity of the auroral zone current. The aspect of the current system, which is obtained by combination of Figs. 4 and 5, shows good agreement with the average current system of bays by H.C. Silsbee and E.H. Vestine [6].

\section{§ 5. Bay disturbances at Honolulu}

As will be seen in vector-diagrams in Fig. 6, the magnitude of disturbance forces at Honolulu $\left(21.1^{\circ} \mathrm{N}\right.$ in geomagnetic latitude) is much small compared with those observed in the middle latitude regions. The disturbance force vector directs almost northward or south ward, showing that bay disturbances can hardly be recognized in the record of declination. The rotation of loops of vector-diagrams at Honolulu does not show such a systematic character

Fig. 4 Progressive change in the overhead current arrows and the current system of the average bay disturbance. 


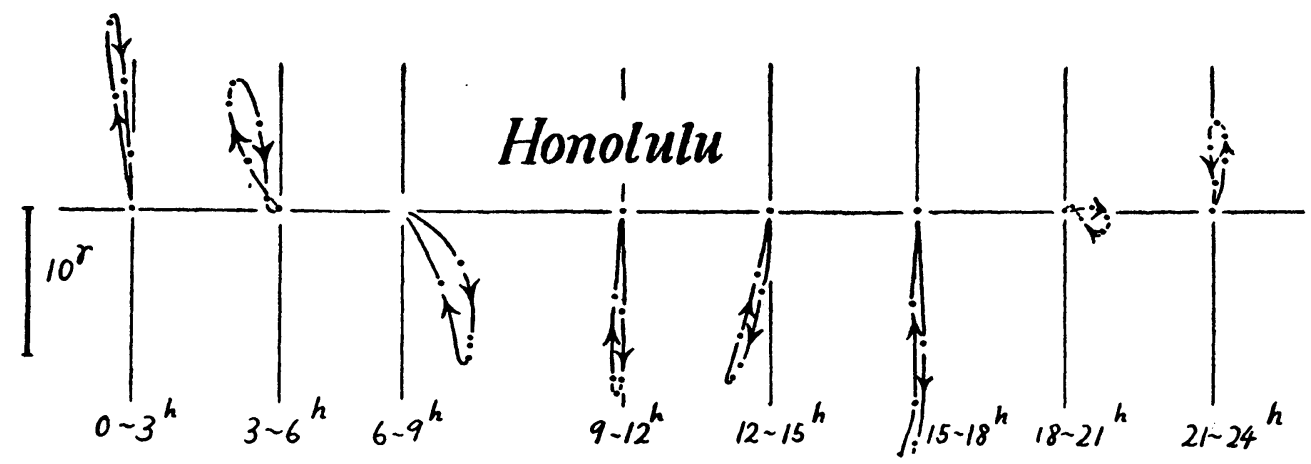

Fig. 6 Vector-diagrams of mean horizontal disturbing forces of geomagnetic bays at Honolulu.

as in the middle latitude regions. This may be perhaps due to an ambiguity in defining the disturbance force of bays, since the disturbances themselves are small there.

\section{§ 6. Conclusion}

In this statistical work, it was obtained that the vector-diagrams, which illustrate the change in the disturbance forces during the course of bays, show the same characteristics everywhere in the middle latitude regions, in America, in Europe and also in Asia; namely the disturbance force vector rotates clockwise in the forenoon and counter-clockwise in the afternoon as described in $\S 3$. The above characteristic corresponds to broadening of the positive bay area during the course of bay as illustrated in Fig. 4. It is also noticed that the average current system tend to shift eastward a little on the whole during its development and decay.

The disturbance force of bays observed at Sitka is fairly affected by the neighbouring auroral zone current. The current system in the polar cap will be supposed to be a similar one to that of Fig. 5 .

The result of frequency, distribution of occurrence of bays suggests that the disturbance force at daytime is rather overestimated and that at night rather underestimated in "the average bay." Hence, the mean current intensity will be somewhat large in the dark hemisphere and weak in the sunlit one in practice, compared with the current distribution of "the average bay." Nevertheless, the above conclusions on the progressive change in the current system for geomagnetic bays will remain without serious alteration.

In concluding, the writers wish to express their hearty thanks to U.S. Coast and Geodetic Survey for sending us "Magnetograms." Their cordial thanks are also due to Prof. T. Nagata for his kind direction throughout this study, and to Messrs. R. Sato, Y. Ono and T. Takano for their assistance in the statistical work.

(Read Apr. 27, 1952)

\section{References}

[1] L. Steiner, Terr. Mag., 26, 1 (1921).

[2] H. Hatakeyama, Geophys. Mag., 12, 15 (1938).

[3] J.M. Princep Curto, Memorias del Observatorio del Ebro, No. 10 (1949).

[4] N. Fukushima, Geophysical Notes, Tokyo Univ., Vol. 3, No. 22 (1950).

[5] T. Nagata and N. Fukushima, Rep. Ionosphere Res. Japan, 6, 85 (1952).

[6] H.C. Silsbee and E.H. Vestine, Terr. Mag., 47, 195 (1942). 